\title{
Syntheses, structure and photoluminescent properties of lanthanide oxalatosulfocarboxylate coordination polymers
}

\author{
LI XinFa*, GAO ZhiXi \& ZENG QiHua \\ Department of Chemistry, Zunyi Normal College, Zunyi 563002, China
}

Received September 11, 2011; accepted September 20, 2011; published online March 12, 2012

\begin{abstract}
Hydrothermal reactions of oxalic acid $\left(\mathrm{H}_{2} \mathrm{Ox}\right)$ and 2-sulfobenzoic acid $\left(\mathrm{H}_{2} \mathrm{~L}\right)$ with lanthanide oxide or hydroxide yielded five lanthanide oxalatosulfocarboxylates. They have a general formula $\left[\mathrm{Ln}_{2} \mathrm{~L}_{2}(\mathrm{ox})\left(\mathrm{H}_{2} \mathrm{O}\right)_{6}\right]_{n}[\mathrm{Ln}=\mathrm{La}(\mathbf{1}), \mathrm{Nd}(\mathbf{2}), \mathrm{Eu}(\mathbf{3}), \mathrm{Gd}(\mathbf{4}), \mathrm{Tb}(\mathbf{5})]$. Their structures were characterized by single crystal X-ray diffraction, powder X-ray diffraction (PXRD), infrared (IR) spectroscopy, elemental analysis (EA), and thermogravimetric analysis (TGA). 1-5 are isostructural coordination polymers and feature one-dimensional (1D) chains, which are extended into 3D supramolecular frameworks through inter-chain hydrogen bonds between coordinated $\mathrm{H}_{2} \mathrm{O}$ donors and oxygen acceptors from carboxylate, sulfonate and oxalate groups. In addition, the solid-state photoluminescence properties of the $\mathrm{Nd}(\mathbf{2}), \mathrm{Eu}(\mathbf{3})$ and $\mathrm{Tb}(\mathbf{5})$ derivatives have been measured at room temperature. The Eu and Tb-containing coordination polymers (CPs) exhibit intense red and green luminescence emissions, respectively, with lifetimes in the order of millisecond.
\end{abstract}

lanthanide oxalate, lanthanide sulfonate, photoluminescence, coordination polymer

Citation: $\quad$ Li X F, Gao Z X, Zeng Q H. Syntheses, structure and photoluminescent properties of lanthanide oxalatosulfocarboxylate coordination polymers. Chin Sci Bull, 2012, 57: 1659-1664, doi: 10.1007/s11434-012-5049-7

Research on design and synthesis of lanthanide-based coordination polymers is currently of great interest, not only because of their aesthetically pleasing structures but also because of their potential applications in areas such as biological assays, medical diagnosis, magnetic resonance imaging reagents, light-emitting materials, laser systems, and optical fibers for telecommunications [1-3]. Trivalent lanthanide ions are fascinating luminescent sources for their high color purity and relatively long lifetimes (millisecond) arising from intra-configurational f-f transitions. Unfortunately, f-f transitions are parity forbidden according to the Laporte selection rules, which results in low molar absorptivities, making direct photo-excitation of Ln (III) ions inefficient, unless high power laser excitation sources are utilized [4]. However, this can be solved via indirect excitation using a $\pi$-conjugated ligand chromophore as luminescence sensitizer. In a typical sensitization process, the ligand is excited through high absorptivity $\pi-\pi^{*}$ transition, which

*Corresponding author (email: xflichem@163.com) then transfers energy to the Ln (III) ion, populating the Lncentered excited state, thus giving the lanthanide emission [5]. This so called "antenna effect" has been well documented for lanthanide complexes based on $\beta$-diketonates, polyazine ligands, microcycle polyamines and aromatic carboxylate ligands [6-18]. Our research group has also reported some luminescent lanthanide complexes constructed from phosphonate, sulfonate, oxalate and carboxylate ligands in recent years [19-21]. The oxalate ligand $\left(\mathrm{H}_{2} \mathrm{Ox}\right)$ chelates to $\mathrm{Ln}$ ions and forms a series of complex lanthanide oxalates, from the commonly known $\operatorname{Ln}\left(\mathrm{C}_{2} \mathrm{O}_{4}\right)_{n}$ ( $n=1-4)$ moieties to the rarely observed $\operatorname{Ln}\left(\mathrm{C}_{2} \mathrm{O}_{4}\right)_{5}$ units $[22,23]$. As an extension of our research on lanthanide oxalates, we have selected $\mathrm{H}_{2} \mathrm{Ox}$ as the primary ligand and 2-sulfobenzoic acid as an auxiliary ligand. Five lanthanide oxalatosulfocarboxylate coordination polymers $(\mathrm{CPs})$ were obtained by the synergistic coordination of $\mathrm{ox}^{2-}$ and 2sulfobenzoic acid to Ln (III) ions under hydrothermal conditions, namely, $\left[\mathrm{Ln}_{2} \mathrm{~L}_{2}(\mathrm{ox})\left(\mathrm{H}_{2} \mathrm{O}\right)_{6}\right]_{n}[\mathrm{Ln}=\mathrm{La}(\mathbf{1}), \mathrm{Nd}(\mathbf{2})$, $\mathrm{Eu}(\mathbf{3}), \mathrm{Gd}(\mathbf{4}), \mathrm{Tb}(\mathbf{5})]$. They were characterized by 
single-crystal X-ray diffractions, powder X-ray diffractions, elemental analyses and IR spectroscopic studies. Solid-state photoluminescence investigations revealed the $\pi$-conjugated 2-sulfobenzoic acid ligand can be a good chromophore as lanthanide luminescence sensitizer.

\section{Experimental}

\subsection{Materials and methods}

All chemicals were obtained from commercial sources and used without further purification. Elemental analyses of $\mathrm{C}$ and $\mathrm{H}$ were measured on a Vario MICRO E III elemental analyzer. Infrared (IR) spectra were recorded on PerkinElmer Spectrum One instrument as $\mathrm{KBr}$ pellets from 4000 to $400 \mathrm{~cm}^{-1}$. Thermogravimetric analyses were performed on an NETZSCH STA 449C unit at a heating rate of $10^{\circ} \mathrm{C} /$ min under a nitrogen atmosphere. X-ray powder diffraction patterns of CPs 1-5 were collected on a Rigaku Mini Flex2 diffractometer using $\mathrm{Cu} \mathrm{K \alpha}$ Radiation $(\lambda=$ $1.54056 \AA$ A ) under ambient conditions. Solid-state photoluminescent spectra of CPs $\mathbf{2}, \mathbf{3}$ and $\mathbf{5}$ were measured at room temperature with an Edinburgh FLS920 fluorescence spectrometer. The instrument is equipped with an Edinburgh Xe900 xenon arc lamp as the excitation light source.

\subsection{Syntheses of CPs 1-5}

A mixture of $\mathrm{Ln}_{2} \mathrm{O}_{3}(0.3 \mathrm{mmol}), \mathrm{H}_{2} \mathrm{C}_{2} \mathrm{O}_{4} \cdot 2 \mathrm{H}_{2} \mathrm{O}(0.3 \mathrm{mmol})$ and 2-sulfobenzoic acid $(0.6 \mathrm{mmol})$ in deionized water $(10$ $\mathrm{mL}$ ) was placed in a $23 \mathrm{~mL}$ Teflon-lined stainless autoclave. After 10 min of stirring, it was sealed and heated at $170^{\circ} \mathrm{C}$ for $108 \mathrm{~h}$, then slowly cooled to room temperature at a rate of $3^{\circ} \mathrm{C} / \mathrm{h}$.

For $1\left(\mathrm{Ln}_{2} \mathrm{O}_{3}=\mathrm{La}_{2} \mathrm{O}_{3}\right)$ : colorless block-shaped crystals were collected by filtration, washed with distilled water and air dried. Yield: $65 \%$ (based on $\mathrm{La}_{2} \mathrm{O}_{3}$ ). Calcd for $\mathrm{C}_{8} \mathrm{H}_{10} \mathrm{LaO}_{10} \mathrm{~S}$ (\%): C, 21.98; H, 2.31. Found (\%): C, 22.02; $\mathrm{H}$, 2.29. IR ( $\left.\mathrm{KBr}, \mathrm{cm}^{-1}\right): 3392$ (vs, br), 1662 (vs), 1533 (vs), 1478 (w), 1415 (s), 1314 (w), 1220 (m), 1181 (s), 1089 (m), $1023(\mathrm{~m}), 868(\mathrm{w}), 794(\mathrm{w}), 663(\mathrm{w})$.

For $2\left(\mathrm{Ln}_{2} \mathrm{O}_{3}=\mathrm{Nd}_{2} \mathrm{O}_{3}\right)$ : light-purple block-shaped crystals were collected by filtration, washed with distilled water and air dried. Yield: $70 \%$ (based on $\mathrm{Nd}_{2} \mathrm{O}_{3}$ ). Calcd for $\mathrm{C}_{8} \mathrm{H}_{10} \mathrm{NdO}_{10} \mathrm{~S}$ (\%): C, 21.72; H, 2.28. Found (\%): C, 21.59; $\mathrm{H}, 2.31$. IR ( $\left.\mathrm{KBr}, \mathrm{cm}^{-1}\right)$ : 3392 (s, br), 1664 (s), 1535 (vs), 1480 (w), 1419 (s), 1314 (w), 1220 (m), 1180 (s), 1090 (w), $1024(\mathrm{w}), 872(\mathrm{w}), 796(\mathrm{w}), 666(\mathrm{w})$.

For $3\left(\mathrm{Ln}_{2} \mathrm{O}_{3}=\mathrm{Eu}_{2} \mathrm{O}_{3}\right)$ : colorless block-shaped crystals were collected by filtration, washed with distilled water and air dried. Yield: $68 \%$ (based on $\mathrm{Eu}_{2} \mathrm{O}_{3}$ ). Calcd for $\mathrm{C}_{8} \mathrm{H}_{10} \mathrm{EuO}_{10} \mathrm{~S}$ (\%): C, 21.34; H, 2.24. Found (\%): C, 21.08; $\mathrm{H}$, 2.17. IR (KBr, cm $\left.{ }^{-1}\right): 3393$ (s, br), 1667 (vs), 1540 (vs), 1482 (w), 1426 (s), 1316 (w), 1219 (w), 1181 (s), 1090 (w), $1024(w), 872(w), 798(w), 665(w)$.
For $4\left(\mathrm{Ln}_{2} \mathrm{O}_{3}=\mathrm{Gd}_{2} \mathrm{O}_{3}\right)$ : colorless block-shaped crystals were collected by filtration, washed with distilled water and air dried. Yield: 66\% (based on $\mathrm{Gd}_{2} \mathrm{O}_{3}$ ). Calcd for $\mathrm{C}_{8} \mathrm{H}_{10} \mathrm{GdO}_{10} \mathrm{~S}(\%): \mathrm{C}, 21.10 ; \mathrm{H}, 2.21$. Found (\%): C, 21.19; H, 2.23. IR (KBr, cm $\left.{ }^{-1}\right): 3392$ (s, br), 1667 (vs), 1541 (vs), $1483(\mathrm{w}), 1427$ (s), $1316(\mathrm{w}), 1219(\mathrm{~m}), 1181$ (s), $1090(\mathrm{w})$, $1024(\mathrm{w}), 873(\mathrm{w}), 799(\mathrm{w}), 666(\mathrm{w})$.

For $5\left(0.6 \mathrm{mmol}\right.$ of $\mathrm{Tb}(\mathrm{OH})_{3}$ was used instead of $\left.\mathrm{Ln}_{2} \mathrm{O}_{3}\right)$ : colorless block-shaped crystals were collected by filtration, washed with distilled water and air dried. Yield: $68 \%$ (based on $\left.\mathrm{Tb}(\mathrm{OH})_{3}\right)$. Calcd for $\mathrm{C}_{8} \mathrm{H}_{10} \mathrm{O}_{10} \mathrm{STb}(\%)$ : C, 21.02; H, 2.20 . Found (\%): C, 20.88; H, 2.27. IR (KBr, $\left.\mathrm{cm}^{-1}\right)$ : 3391 (s, br), 1668 (vs), 1543 (vs), 1484 (w), 1428 (s), 1316 (w), 1217 (m), 1180 (s), 1090 (w), 1024 (w), $872(\mathrm{w}), 800$ (w), 666 (w).

\subsection{X-ray crystallographic study}

Crystal structure determinations of CPs 1-5 were performed on Oxford Xcalibur E CCD-based diffractometers equipped with graphite-monochromated Mo-K $\alpha$ radiation $(\lambda=0.71073$ $\AA$ ) at room temperature. The intensity data sets were collected with $\omega$-scan technique. The CrysAlisPro (Version 1.171.34.49) software was used for data reduction and empirical absorption correction. The structures were solved by direct methods and successive Fourier difference syntheses, and refined by full-matrix least-squares on $F^{2}$ (SHELXTL Version 5.1) [24]. All non-hydrogen atoms were refined with anisotropic displacement parameters. Hydrogen atoms attached to $\mathrm{C}$ atoms were generated geometrically and refined by a riding-mode with isotropic thermal parameters fixed at 1.2 times that of the mother atoms. Hydrogen atoms bonding to coordinated water molecules were placed on calculated positions and refined with isotropic thermal parameters fixed at 1.5 times that of the $\mathrm{O}$ atoms. The detailed crystallographic data and structure refinement parameters of CPs 1-5 are summarized in Table 1. Selected bond lengths are listed in Table 2.

\section{Results and discussion}

\subsection{Crystal structure of CPs 1-5}

Single-crystal X-ray diffractions, powder X-ray diffractions (Figure 1), elemental analyses and IR spectroscopic studies performed on 1-5 reveal that they are isostructural, with variations in the crystal unit cell volumes and Ln-O bond lengths decreasing from $\mathrm{La} \mathrm{(1)} \mathrm{to} \mathrm{Tb}(\mathbf{5})$ (Tables 1 and 2), because of the lanthanide contraction effect. Therefore, $\mathbf{3}$ is described here representatively to illustrate the structures. $\mathbf{3}$ crystallized in the $P \overline{1}$ space group. As shown in Figure 2, the asymmetric unit of $\mathbf{3}$ consists of one $\mathrm{Eu}(\mathrm{III})$ ion, one $\mathrm{L}^{2-}$ ligand, a half occupancy ox ${ }^{2-}$ ligand on an inversion center and three coordinated water molecules. All atoms lie in general positions. The $\mathrm{Eu}(\mathrm{III})$ ion is nine-coordinate with an 
Table 1 Crystallographic data for CPs 1-5

\begin{tabular}{lccccc}
\hline \multicolumn{1}{c}{$\mathrm{CP}$} & $\mathbf{1}$ & $\mathbf{2}$ & $\mathbf{3}$ & $\mathbf{4}$ & $\mathbf{5}$ \\
\hline Empirical formula & $\mathrm{C}_{8} \mathrm{H}_{10} \mathrm{LaO}_{10} \mathrm{~S}$ & $\mathrm{C}_{8} \mathrm{H}_{10} \mathrm{NdO}_{10} \mathrm{~S}$ & $\mathrm{C}_{8} \mathrm{H}_{10} \mathrm{EuO}_{10} \mathrm{~S}$ & $\mathrm{C}_{8} \mathrm{H}_{10} \mathrm{GdO}_{10} \mathrm{~S}$ & $\mathrm{C}_{8} \mathrm{H}_{10} \mathrm{O}_{10} \mathrm{STb}$ \\
Formula weight & 437.13 & 442.46 & 450.18 & 455.47 & 457.14 \\
Crystal system & Triclinic & Triclinic & Triclinic & Triclinic & Triclinic \\
Space group & $P \overline{1}$ & $P \overline{1}$ & $P \overline{1}$ & $P \overline{1}$ & $P \overline{1}$ \\
$a(\AA)$ & $7.8239(4)$ & $7.7830(4)$ & $7.7588(5)$ & $7.7480(5)$ & $7.7312(3)$ \\
$b(\AA)$ & $8.6649(8)$ & $8.5820(4)$ & $8.5154(4)$ & $8.4834(7)$ & $8.4507(7)$ \\
$c(\AA)$ & $10.8262(7)$ & $10.7097(5)$ & $10.6518(7)$ & $10.6320(8)$ & $10.6403(8)$ \\
$\alpha\left(^{(}\right)$ & $70.125(7)$ & $70.505(4)$ & $70.875(5)$ & $70.992(7)$ & $71.218(7)$ \\
$\beta\left({ }^{\circ}\right)$ & $87.220(5)$ & $87.445(4)$ & $87.814(5)$ & $87.879(6)$ & $88.075(5)$ \\
$\gamma\left({ }^{\circ}\right)$ & $70.710(6)$ & $70.530(5)$ & $70.337(5)$ & $70.382(6)$ & $70.392(6)$ \\
$V\left(\AA^{3}\right)$ & $649.79(8)$ & $633.98(5)$ & $624.08(6)$ & $620.32(8)$ & $617.83(7)$ \\
$Z$ & 2 & 2 & 2 & 2 & 2 \\
$D_{c}\left(\mathrm{~g} \mathrm{~cm}^{-3}\right)$ & 2.234 & 2.318 & 2.396 & 2.439 & 2.457 \\
$\mu\left(\mathrm{mm}^{-1}\right)$ & 3.495 & 4.308 & 5.241 & 5.563 & 5.942 \\
$R($ int $)$ & 0.0387 & 0.0383 & 0.0237 & 0.0380 & 0.0390 \\
$\mathrm{GOF}$ on $F^{2}$ & 1.005 & 1.002 & 1.004 & 1.004 & 1.007 \\
$R_{1}, w R_{2}(I>2 \sigma(I))^{\mathrm{a})}$ & $0.0259,0.0611$ & $0.0294,0.0574$ & $0.0228,0.0696$ & $0.0305,0.0742$ & $0.0376,0.0889$ \\
$\Delta \rho_{\text {min/max }}\left(\mathrm{e} / \AA^{3}\right)$ & $1.005 /-0.939$ & $1.152 /-0.735$ & $0.646 /-1.138$ & $1.718 /-1.531$ & $2.877 /-1.374$ \\
\hline
\end{tabular}

a) $\left.R=\sum|| F_{0}|-| \mathrm{F}_{\mathrm{c}} \mid\right) / \sum\left|F_{0}\right|, w R=\left[\sum w\left(F_{0}^{2}-F_{\mathrm{c}}{ }^{2}\right)^{2} / \sum w\left(F_{0}^{2}\right)^{2}\right]^{1 / 2}$.

Table 2 Selected bond lengths $(\AA)$

\begin{tabular}{|c|c|c|c|}
\hline CP 1 & & & \\
\hline $\mathrm{La}(1)-\mathrm{O}(1)$ & $2.486(3)$ & $\mathrm{La}(1)-\mathrm{O}(10)$ & $2.501(3)$ \\
\hline $\mathrm{La}(1)-\mathrm{O}(3)$ & $2.512(3)$ & $\mathrm{La}(1)-\mathrm{O}(6)$ & $2.518(3)$ \\
\hline $\mathrm{La}(1)-\mathrm{O}(7) \# 1^{\mathrm{a})}$ & $2.540(3)$ & $\mathrm{La}(1)-\mathrm{O}(2) \# 2$ & $2.557(3)$ \\
\hline $\mathrm{La}(1)-\mathrm{O}(9)$ & $2.560(3)$ & $\mathrm{La}(1)-\mathrm{O}(8)$ & $2.574(3)$ \\
\hline $\mathrm{La}(1)-\mathrm{O}(1) \# 2^{\mathrm{a})}$ & $2.789(3)$ & & \\
\hline \multicolumn{4}{|l|}{ CP 2} \\
\hline $\mathrm{Nd}(1)-\mathrm{O}(1)$ & $2.424(3)$ & $\mathrm{Nd}(1)-\mathrm{O}(10)$ & $2.434(3)$ \\
\hline $\mathrm{Nd}(1)-\mathrm{O}(3)$ & $2.457(3)$ & $\mathrm{Nd}(1)-\mathrm{O}(6)$ & $2.468(3)$ \\
\hline $\mathrm{Nd}(1)-\mathrm{O}(7) \# 1^{\text {a) }}$ & $2.481(3)$ & $\mathrm{Nd}(1)-\mathrm{O}(2) \# 2$ & $2.484(3)$ \\
\hline $\mathrm{Nd}(1)-\mathrm{O}(9)$ & $2.503(3)$ & $\mathrm{Nd}(1)-\mathrm{O}(8)$ & $2.524(3)$ \\
\hline $\mathrm{Nd}(1)-\mathrm{O}(1) \# 2^{\mathrm{a})}$ & $2.777(3)$ & & \\
\hline \multicolumn{4}{|l|}{ CP 3} \\
\hline $\mathrm{Eu}(1)-\mathrm{O}(1)$ & $2.382(3)$ & $\mathrm{Eu}(1)-\mathrm{O}(10)$ & $2.383(4)$ \\
\hline $\mathrm{Eu}(1)-\mathrm{O}(3)$ & $2.424(3)$ & $\mathrm{Eu}(1)-\mathrm{O}(6)$ & $2.427(3)$ \\
\hline $\mathrm{Eu}(1)-\mathrm{O}(7) \# 1^{\text {a) }}$ & $2.438(4)$ & $\mathrm{Eu}(1)-\mathrm{O}(2) \# 2$ & $2.451(4)$ \\
\hline $\mathrm{Eu}(1)-\mathrm{O}(9)$ & $2.462(4)$ & $\mathrm{Eu}(1)-\mathrm{O}(8)$ & $2.484(4)$ \\
\hline $\mathrm{Eu}(1)-\mathrm{O}(1) \# 2^{\text {a) }}$ & $2.805(3)$ & & \\
\hline \multicolumn{4}{|l|}{$\mathrm{CP} 4$} \\
\hline $\mathrm{Gd}(1)-\mathrm{O}(1)$ & $2.369(3)$ & $\mathrm{Gd}(1)-\mathrm{O}(10)$ & $2.370(4)$ \\
\hline $\mathrm{Gd}(1)-\mathrm{O}(7) \# 1^{\text {a) }}$ & $2.410(4)$ & $\mathrm{Gd}(1)-\mathrm{O}(3)$ & $2.414(4)$ \\
\hline $\mathrm{Gd}(1)-\mathrm{O}(6)$ & $2.423(4)$ & $\mathrm{Gd}(1)-\mathrm{O}(2) \# 2$ & $2.431(4)$ \\
\hline $\mathrm{Gd}(1)-\mathrm{O}(9)$ & $2.453(4)$ & $\mathrm{Gd}(1)-\mathrm{O}(8)$ & $2.478(4)$ \\
\hline $\mathrm{Gd}(1)-\mathrm{O}(1) \# 2^{\mathrm{a})}$ & $2.811(4)$ & & \\
\hline \multicolumn{4}{|l|}{ CP 5} \\
\hline $\mathrm{Tb}(1)-\mathrm{O}(1)$ & $2.345(5)$ & $\mathrm{Tb}(1)-\mathrm{O}(10)$ & $2.348(5)$ \\
\hline $\mathrm{Tb}(1)-\mathrm{O}(3)$ & $2.397(5)$ & $\mathrm{Tb}(1)-\mathrm{O}(7) \# 1$ & $2.401(5)$ \\
\hline $\mathrm{Tb}(1)-\mathrm{O}(6)$ & $2.413(5)$ & $\mathrm{Tb}(1)-\mathrm{O}(2) \# 2$ & $2.420(5)$ \\
\hline $\mathrm{Tb}(1)-\mathrm{O}(9)$ & $2.438(6)$ & $\mathrm{Tb}(1)-\mathrm{O}(8)$ & $2.460(5)$ \\
\hline $\mathrm{Tb}(1)-\mathrm{O}(1) \# 2^{\mathrm{a})}$ & $2.852(5)$ & & \\
\hline
\end{tabular}

a) Symmetry codes. for $1, \# 1:-x+1,-y,-z$. \#2: $-x+1,-y+1,-z ; 2, \# 1$ : $-x+1,-y+2,-z+1$. \#2: $-x+1,-y+1,-z+1 ; 3, \# 1:-x+1,-y,-z . \# 2:-x+1$, $-y+1,-z ; \mathbf{4}, \# 1:-x,-y+1,-z+1$. \#2: $-x,-y,-z+1 ; \mathbf{5}, \# 1:-x+1,-y+1,-z+1$. $\# 2:-x+1,-y,-z+1$.

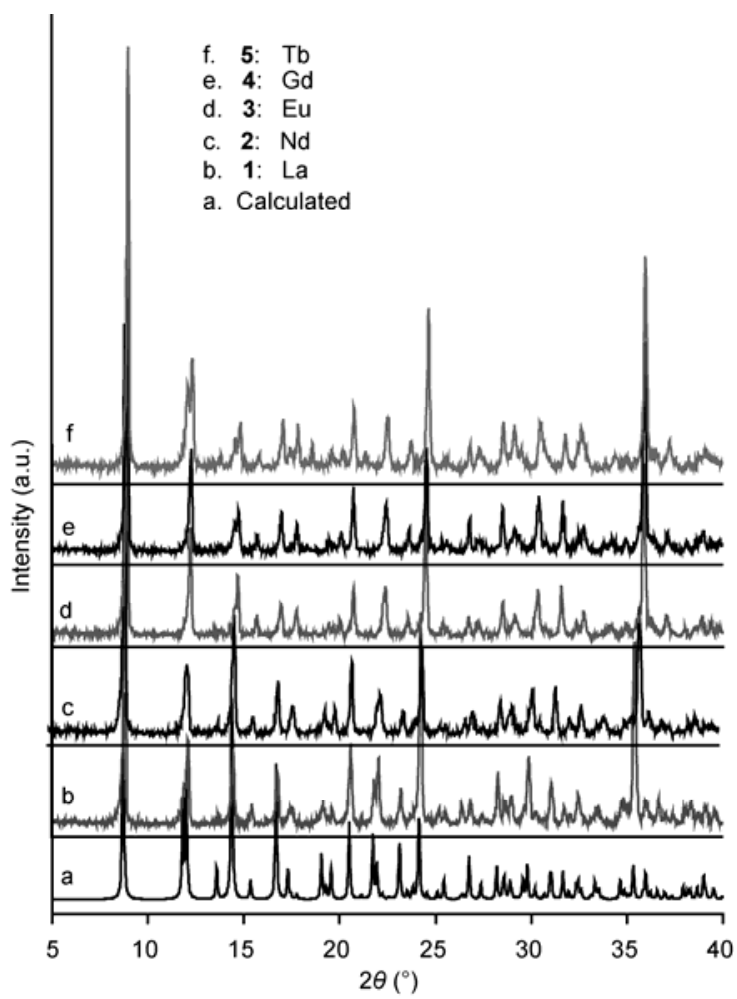

Figure 1 Calculated and experimental XRD powder patterns of 1-5.

$\mathrm{O}_{9}$ donor set and the coordination polyhedron $\left[\mathrm{EuO}_{9}\right]$ can be best described as a slightly distorted monocapped square antiprism. Four of the oxygen atoms come from the carboxylate and sulfonate groups of two equivalent $\mathrm{L}^{2-}$ ligands, and the other five oxygen atoms come from a chelating $\mathrm{ox}^{2-}$ ligand and the three coordinated water molecules. The Eu-O bond lengths range from $2.382(3)$ to $2.805(3) \AA$, with an 


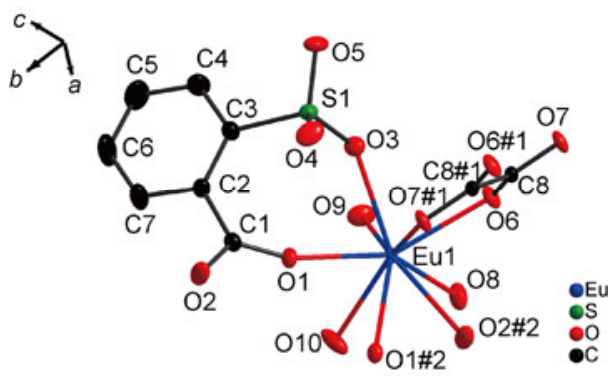

Figure 2 (Color online) Asymmetric unit of $\mathbf{3}$ with $50 \%$ probability thermal ellipsoids (\#1: $-x+1,-y,-z ; \# 2:-x+1,-y+1,-z$ ). Hydrogen atoms have been omitted for clarity.

average value of about 2.473(1) $\AA$. The ox ${ }^{2-}$ ligand adopts the most commonly observed bis-bidentate coordination mode, chelating to two $\mathrm{Eu}(\mathrm{III})$ ions and forming two edgesharing five-membered rings (Eu-O-C-C-O). $\mathrm{L}^{2-}$ ligand chelates to an $\mathrm{Eu}(\mathrm{III})$ ion using its carboxylate group and chelates to another $\mathrm{Eu}(\mathrm{III})$ ion via one of its carboxylate oxygen atoms and one of its sulfonate oxygen atoms, generating a centrosymmetric dimer $\left[\mathrm{Eu}_{2}(\mathrm{~L})_{2}\right]^{2+}$. The Eu-Eu $(1-x$, $1-y,-z)$ distance within the dimmer is $4.379 \AA$. The dimer is bridged by an ox ${ }^{2-}$ ligand forming a $1 \mathrm{D}$ "zigzag" chain running along the $b$-axis (Figure 3). At the supramolecular level, inter-chain hydrogen bonds between the coordinated $\mathrm{H}_{2} \mathrm{O}$ donors and oxygen acceptors on the carboxylate, sulfonate and oxalate groups link the 1D coordination polymer into a 3D supramolecular framework as shown in Figure 4. The $\mathrm{O}(\mathrm{D}) \cdots \mathrm{O}(\mathrm{A})$ distances range from 2.627 to $3.075 \AA$. Detailed hydrogen bonding information is listed in Table 3.

\subsection{Thermogravimetric analysis}

CPs 1-3 were selected to examine the thermal stabilities of these coordination polymers. Thermogravimetric analysis (TGA) was measured in a nitrogen atmosphere from 40 to $900^{\circ} \mathrm{C}$ at a heating rate of $10^{\circ} \mathrm{C} / \mathrm{min}$. As shown in Figure 5, they displayed very similar thermal decomposition processes. 2 will be described as a representative to depict them all in detail. The TGA curve of $\mathbf{2}$ displays two main stages of weight losses. The weight loss from 85 to $210^{\circ} \mathrm{C}$ of $11.9 \%$ corresponds to the loss of the three coordinated water molecules (theoretical value $12.2 \%$ ). The mass then remains stable until $355^{\circ} \mathrm{C}$. The second weight loss stage occurs from 360 to $560^{\circ} \mathrm{C}$, where the curve shows a sharp drop (32.3\% weight loss), indicating the decomposition of the

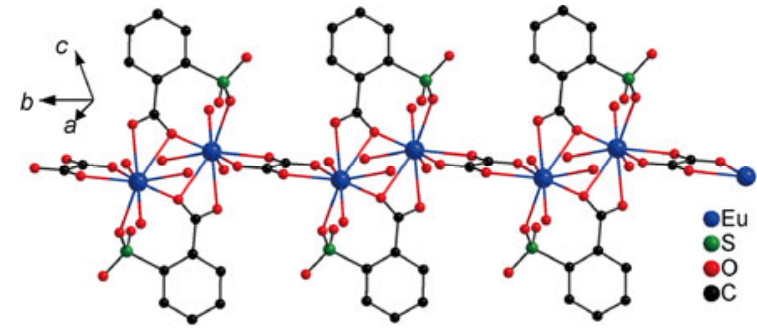

Figure 3 (Color online) $\left[\mathrm{Eu}_{2}(\mathrm{~L})_{2}\right]^{2+}$ dimer linked by $\mathrm{ox}^{2-}$ ligand along the crystallographic $b$-axis forming a 1D coordination polymer. Hydrogen atoms have been omitted for clarity.

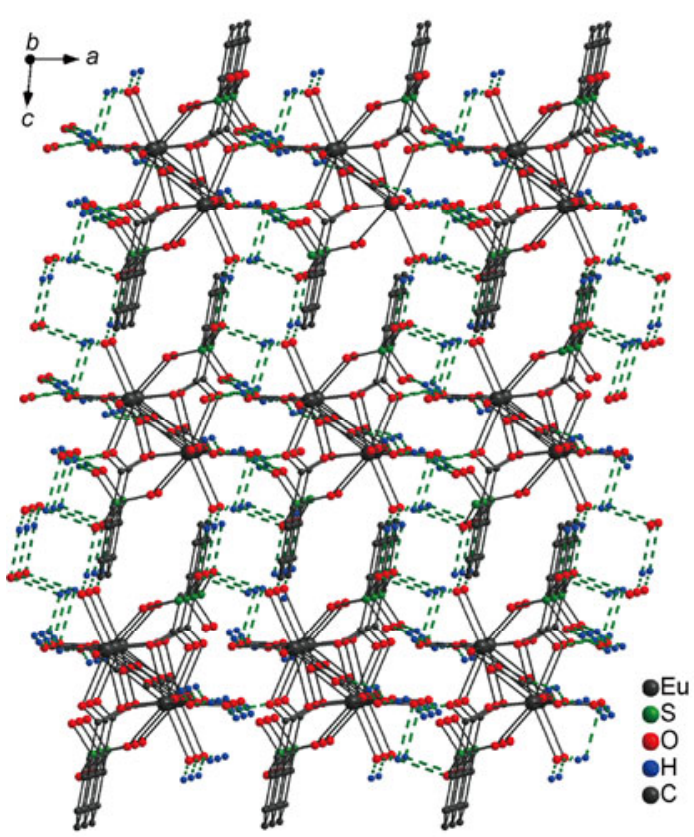

Figure 4 (Color online) View of the 3D supramolecular structure of $\mathbf{3}$ along the crystallographic $b$-axis. Hydrogen bonds are drawn as green dashes.

backbone of the 1D coordination polymer. The coordination polymer then decomposes slowly above this temperature and complete decomposition is not achieved until above $900^{\circ} \mathrm{C}$.

\subsection{Photoluminescence properties}

Trivalent Eu- and $\mathrm{Tb}$-containing complexes show strong and characteristic luminescent emissions in the visible region with long-lived (millisecond timescale) excited states, making them to be good candidate materials as chemical

Table 3 Hydrogen bond parameters $(\AA)$ in $\mathbf{3}^{\text {a) }}$

\begin{tabular}{|c|c|c|c|}
\hline $\mathrm{D}-\mathrm{H} \cdots \mathrm{A}$ & $\mathrm{D} \cdots \mathrm{A}$ distance & $\mathrm{D}-\mathrm{H} \cdots \mathrm{A}$ & D $\cdots$ A distance \\
\hline $\mathrm{O}(8)-\mathrm{H}(8 \mathrm{~B}) \cdots \mathrm{O}(2) \# 3$ & $2.771(5)$ & $\mathrm{O}(8)-\mathrm{H}(8 \mathrm{~A}) \cdots \mathrm{O}(4) \# 4$ & $2.990(5)$ \\
\hline $\mathrm{O}(9)-\mathrm{H}(9 \mathrm{~B}) \cdots \mathrm{O}(5) \# 4$ & $3.075(6)$ & $\mathrm{O}(9)-\mathrm{H}(9 \mathrm{~A}) \cdots \mathrm{O}(5) \# 5$ & $2.788(5)$ \\
\hline
\end{tabular}

a) Symmetry codes. \#3: $x+1, y-1, z$; \#4: $x+1, y, z ; \# 5:-x+1,-y,-z+1$; \#6: $x, y+1, z$. 


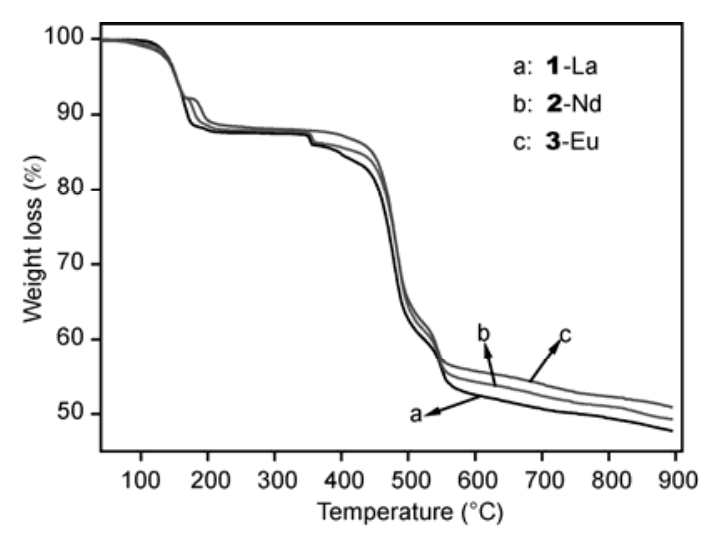

Figure 5 Thermogravimetric analysis (TGA) curves of CPs 1-3.

sensors, fluoroimmunoassays and structural probes [25]. $\mathrm{Nd}$ (III)-based compounds show emissions in the nearfrared region (800-1400 nm), which has lead to their widespread application in areas such as laser systems, medical diagnosis and telecommunications [26,27]. Bearing this in mind, we measured the solid-state photoluminescent spectra of CPs 3, $\mathbf{5}$ and $\mathbf{2}$ at room temperature.

As displayed in Figure 6, CP 3 exhibits the strong and characteristic emission spectrum of Eu (III) ions upon the excitation at $394 \mathrm{~nm}$. The emission bands occurring at 579 (w), $592(\mathrm{~m}), 616(\mathrm{vs}), 653(\mathrm{w})$ and $697 \mathrm{~nm}(\mathrm{~m})$ can be assigned to ${ }^{5} \mathrm{D}_{0} \rightarrow{ }^{7} \mathrm{~F}_{J}(J=0,1,2,3,4)$ transitions. The spectrum is dominated by the ${ }^{5} \mathrm{D}_{0} \rightarrow{ }^{7} \mathrm{~F}_{2}$ transition at $616 \mathrm{~nm}$, which gave a strong red luminescent output for the sample. The ${ }^{5} \mathrm{D}_{0} \rightarrow{ }^{7} \mathrm{~F}_{2}$ transition of Eu (III) ion is electric dipole (ED) and extremely sensitive to chemical bonds around the $\mathrm{Eu}(\mathrm{III})$ ion. The emission intensity has previously been found to increase as the site symmetry of Eu(III) ion decreases, suggesting a strong symmetry dependence for the ${ }^{5} \mathrm{D}_{0} \rightarrow{ }^{7} \mathrm{~F}_{2}$ transition. In contrast, the ${ }^{5} \mathrm{D}_{0} \rightarrow{ }^{7} \mathrm{~F}_{1}$ transition whose emission intensity is mainly dependent on the crystal field around the $\mathrm{Eu}(\mathrm{III})$ ion is magnetic dipole (MD) and insensitive to site symmetry. As shown in the emission spectrum,

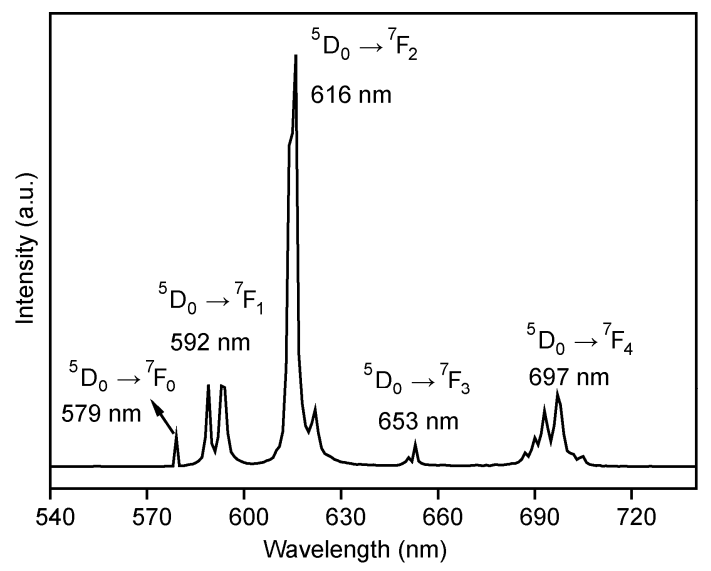

Figure 6 Solid-state emission spectrum of $\mathbf{3}$ at room temperature (excitation at $394 \mathrm{~nm})$. the intensity of the ${ }^{5} \mathrm{D}_{0} \rightarrow{ }^{7} \mathrm{~F}_{2}$ transition is about 4.5 times stronger than that of the ${ }^{5} \mathrm{D}_{0} \rightarrow{ }^{7} \mathrm{~F}_{1}$ transition, indicating there is no inversion center at the $\mathrm{Eu}(\mathrm{III})$ sites, well consistent with the result of the single crystal X-ray diffraction analysis. According to the ED selection rule, the crystal-field $\mathrm{J}$ mixing induced ${ }^{5} \mathrm{D}_{0} \rightarrow{ }^{7} \mathrm{~F}_{0}$ transition is strictly forbidden in a field of high symmetry. The observation of the ${ }^{5} \mathrm{D}_{0} \rightarrow{ }^{7} \mathrm{~F}_{0}$ transition in the emission spectrum is further spectroscopic evidence of the $C_{1}$ site symmetry of the $\mathrm{Eu}$ (III) ion in the crystal structure. The luminescence decay curve of $\mathbf{3}$ was recorded at room temperature. The decay curve can be fitted with a single-exponential function $\left(I=I_{0} \exp (-t / \tau)\right)$. The corresponding lifetime of the excited ${ }^{5} \mathrm{D}_{0}$ state of the $\mathrm{Eu}(\mathrm{III})$ ions was $0.24 \mathrm{~ms}$ by monitoring the ${ }^{5} \mathrm{D}_{0} \rightarrow{ }^{7} \mathrm{~F}_{2}$ transition.

Under ultraviolet excitation at $318 \mathrm{~nm}, \mathrm{CP} 5$ gave typical $\mathrm{Tb}$ (III) emissions from 480 to $640 \mathrm{~nm}$ as shown in Figure 7. These emissions are attributed to the transition from the excited ${ }^{5} \mathrm{D}_{4}$ state to the different $J$-levels of the lower ${ }^{7} \mathrm{~F}_{\mathrm{J}}$ state: ${ }^{5} \mathrm{D}_{4} \rightarrow{ }^{7} \mathrm{~F}_{6}$ at $491 \mathrm{~nm},{ }^{5} \mathrm{D}_{4} \rightarrow{ }^{7} \mathrm{~F}_{5}$ at $544 \mathrm{~nm},{ }^{5} \mathrm{D}_{4} \rightarrow{ }^{7} \mathrm{~F}_{4}$ at $588 \mathrm{~nm}$ and ${ }^{5} \mathrm{D}_{4} \rightarrow{ }^{7} \mathrm{~F}_{3}$ at $621 \mathrm{~nm}$. The spectrum is dominated by the ${ }^{5} \mathrm{D}_{4} \rightarrow{ }^{7} \mathrm{~F}_{5}$ transition, which gave a strong green luminescent output for the sample. The luminescence decay curve of 5 follows a single-exponential function $\left(I=I_{0} \exp \right.$ $(-t / \tau))$. The room temperature lifetime of the excited ${ }^{5} \mathrm{D}_{4}$ states of the $\mathrm{Tb}$ (III) ions was $0.75 \mathrm{~ms}$ by monitoring the ${ }^{5} \mathrm{D}_{4}$ $\rightarrow{ }^{7} \mathrm{~F}_{5}$ transition. CP 2 displayed the characteristic fluorescent emission bands for Nd (III) ion upon visible light excitation at $470 \mathrm{~nm}$ : a medium intensity emission band centered at $894 \mathrm{~nm}\left({ }^{4} \mathrm{~F}_{3 / 2} \rightarrow{ }^{4} \mathrm{I}_{9 / 2}\right)$, a strong emission band at $1059 \mathrm{~nm}\left({ }^{4} \mathrm{~F}_{3 / 2} \rightarrow{ }^{4} \mathrm{I}_{11 / 2}\right)$, and a weak band at $1342 \mathrm{~nm}\left({ }^{4} \mathrm{~F}_{3 / 2} \rightarrow\right.$ ${ }^{4} \mathrm{I}_{13 / 2}$ ) in the near-infrared region (Figure 8). However, no usable luminescence decay curve could be recorded for $\mathbf{2}$ probably because of the fluorescent nature of the ${ }^{4} \mathrm{~F}_{3 / 2} \rightarrow{ }^{4} \mathrm{I}_{\mathrm{J}}$ transition and the non-radioactive relaxation of the excited ${ }^{4} \mathrm{~F}_{3 / 2}$ state by $\mathrm{O}-\mathrm{H}$ harmonic oscillators around the $\mathrm{Nd}$ emission center, since there are three water molecules in the first coordination sphere of the $\mathrm{Nd}$ (III) ion.

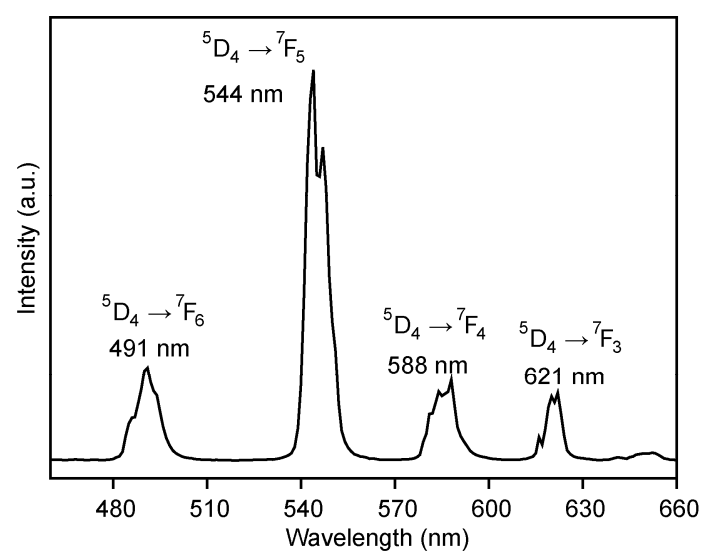

Figure 7 Solid-state emission spectrum of 5 at room temperature (excitation at $318 \mathrm{~nm}$ ). 


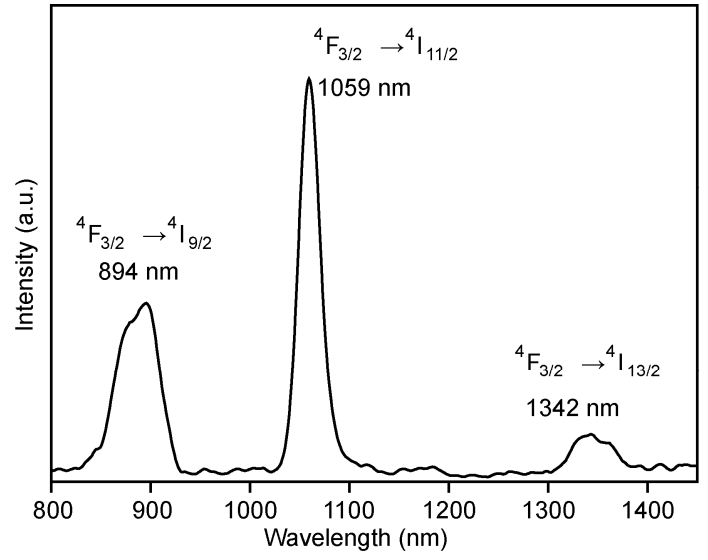

Figure 8 Solid-state emission spectrum of $\mathbf{2}$ at room temperature (excitation at $470 \mathrm{~nm}$ ).

\section{Conclusions}

Five lanthanide oxalatosulfocarboxylate coordination polymers $\left[\mathrm{Ln}_{2} \mathrm{~L}_{2}(\mathrm{ox})\left(\mathrm{H}_{2} \mathrm{O}\right)_{6}\right]_{n}[\mathrm{Ln}=\mathrm{La}(\mathbf{1}), \mathrm{Nd}(\mathbf{2}), \mathrm{Eu}(\mathbf{3}), \mathrm{Gd}$ (4), $\mathrm{Tb}(\mathbf{5})]$ were synthesized and characterized by X-ray diffractions, TGA, IR and EA. Their structures feature 1D oxalate-linked "zigzag" chains containing centrosymmetric dimer $\left[\operatorname{Ln}_{2}(\mathrm{~L})_{2}\right]^{2+}$, which is further extended into 3D supramolecular structure by inter-chain hydrogen bonds. Solidstate photoluminescence studies performed on the $\mathrm{Nd}, \mathrm{Eu}$, and $\mathrm{Tb}$ analogues revealed that the $\pi$-conjugated 2 sulfobenzoic acid ligand can effectively sensitize lanthanide luminescence emissions. CPs $\mathbf{3}$ and $\mathbf{5}$ may be good candidates as efficient red and green light-emitting materials, respectively, while CP 2 could be used as a near-infrared emitter.

This work was supported by the Science and Technology Department of Guizhou Province (J[2010]2121) and Zunyi Science and Technology Bureau $([2010] 04)$

1 Aime S, Castelli D, Crich S, et al. Pushing the sensitivity envelope of lanthanide-based magnetic resonance imaging (MRI) contrast agents for molecular imaging applications. Acc Chem Res, 2009, 42: 822-831

2 Bunzli J C, Piguet C. Taking advantage of luminescent lanthanide ions. Chem Soc Rev, 2005, 34: 1048-1077

3 Eliseeva S V, Bunzli J C. Lanthanide luminescence for functional materials and bio-sciences. Chem Soc Rev, 2010, 39: 189-227

4 Irfanullah M, Iftikhar K. The correlation between f-f absorption and sensitizedvisible light emission of luminescent $\operatorname{Pr}(\mathrm{III})$ complexes: Role of solvents and ancillary ligands on sensitivity. J Fluoresc, 2011, 21: 673-686

5 Moore E G, Samuel A P S, Raymond K N. From antenna to assay: Lessons learned in lanthanide luminescence. Acc Chem Res, 2009, 42: $542-552$

6 Binnemans K. Lanthanide-based luminescent hybrid materials. Chem Rev, 2009, 109: 4283-4374

7 Swavey S, Swavey R. Dinuclear and polynuclear lanthanide coordination complexes containing polyazine ligands: Synthesis and lumi- nescent properties. Coord Chem Rev, 2009, 253: 2627-2638

8 Zhu X D, Lu J, Li X J, et al. Syntheses, structures, near-infrared, and visible luminescence of lanthanide-organic frameworks with flexible macrocyclic polyamine ligands. Cryst Growth Des, 2008, 8: 1897-1901

9 Mao J G. Structures and luminescent properties of lanthanide phosphonates. Coord Chem Rev, 2007, 251: 1493-1520

10 Du Z Y, Xu H B, Mao J G. Rational design of 0D, 1D, and 3D open frameworks based on tetranuclear lanthanide(III) sulfonate-phosphonate clusters. Inorg Chem, 2006, 45: 9780-9788

11 Yang J, Yue Q, Li G D, et al. Structures, photoluminescence, upconversion, and magnetism of $2 \mathrm{D}$ and $3 \mathrm{D}$ rare-earth coordination polymers with multicarboxylate linkages. Inorg Chem, 2006, 45: 2857-2865

12 Wang M X, Long L S, Huang R B, et al. Influence of halide ions on the chirality and luminescent property of ionothermally synthesized lanthanide-based metal-organic frameworks. Chem Commun, 2011, 47: 9834-9836

13 Liu T F, Zhang W J, Sun W H, et al. Conjugated ligands modulated sandwich structures and luminescence properties of lanthanide metalorganic frameworks. Inorg Chem, 2011, 50: 5242-5248

14 Zeng R H, Peng G, Qiu Y C, et al. Synthesis, crystal structures and properties of $\mathrm{Ln}(\mathrm{III})-\mathrm{Cu}(\mathrm{I})-\mathrm{Na}(\mathrm{I})$ and $\mathrm{Ln}(\mathrm{III}-\mathrm{Ag}(\mathrm{I})$ heterometallic coordination polymers. CrystEngComm, 2011, 13: 3910-3919

15 Chen M, Chen M S, Okamura T, et al. A series of silver(I)-lanthanide (III) heterometallic coordination polymers: Syntheses, structures and photoluminescent properties. CrystEngComm, 2011, 13: 3801-3810

16 Wu M F, Wang M S, Guo S P, et al. Photoluminescent and magnetic properties of a series of lanthanide coordination polymers with $1 H$-tetrazolate-5-formic acid. Cryst Growth Des, 2011, 11: 372-381

17 Cepeda J, Balda R, Beobide G, et al. Lanthanide(III)/pyrimidine4,6-dicarboxylate/oxalate extended frameworks: A detailed study based on the lanthanide contraction and temperature effects. Inorg Chem, 2011, 50: 8437-8451

18 Sivakumar S, Reddy M L P, Cowley A H, et al. Lanthanide-based coordination polymers assembled from derivatives of 3,5-dihydroxy benzoates: Syntheses, crystal structures, and photophysical properties. Inorg Chem, 2011, 50: 4882-4891

19 Li X F, Xie Z L, Cao R, et al. Lanthanide-organic frameworks constructed from multi-functional ligands: Syntheses, structures, nearinfrared and visible photoluminescence properties. J Solid State Chem, 2009, 182: 2290-2297

20 Li X F, Liu T F, Lin Q P, et al. Rare earth metal oxalatophosphonates: Syntheses, structure diversity, and photoluminescence properties. Cryst Growth Des, 2010, 10: 608-617

21 Li X F, Cao R, Li Y F. Three dimensional lanthanide-organic frameworks containing tetranuclear $\mathrm{Ln}(\mathrm{Ln}=\mathrm{La}, \mathrm{Nd})$ cluster secondary building blocks. Inorg Chem Commun, 2009, 12: 667-671

22 Baisch U, Braga D. $\left[\mathrm{Yb}\left(\mathrm{C}_{2} \mathrm{O}_{4}\right)_{4}\right]^{5-}$ a versatile metal-organic building block for layered coordination polymers. CrystEngComm, 2009, 11: 40-42

23 Mohanu A, Brouca-Cabarrecq C, Trombe J C. New open-framework three-dimensional lanthanide oxalates containing as a template the diprotonated 1,2- or 1,3-diaminopropane. J Solid State Chem, 2006, 179: 3-17

24 Sheldrick G M. SHELXS-97: Program for refinement of crystal structures. Göttingen: University of Göttingen, 1997

25 Armelao L, Quici S, Barigelletti F, et al. Design of luminescent lanthanide complexes: From molecules to highly efficient photo-emitting materials. Coord Chem Rev, 2010, 254: 487-505

26 Rocha J, Carlos L D, Almeida Paza F A, et al. Luminescent multifunctional lanthanides-based metal-organic frameworks. Chem Soc Rev, 2011, 40: 926-940

27 Bunzli J C, Eliseeva S V. Lanthanide NIR luminescence for telecommunications, bioanalyses and solar energy conversion. J Rare Earths, 2010, 28: 824-842

Open Access This article is distributed under the terms of the Creative Commons Attribution License which permits any use, distribution, and reproduction in any medium, provided the original author(s) and source are credited. 